\title{
COOPERAÇÃO INTERMUNICIPAL NA FRANÇA E NO BRASIL EM PERSPECTIVA COMPARADA
}

\author{
the inter-municipal cooperation in France and Brazil in comparative perspective
}

\author{
Juliana Nunes Rodrigues*
}

\begin{abstract}
Resumo
O presente estudo aborda as práticas de cooperação intermunicipal que se desenvolvem na França e no Brasil. Argumenta-se sobre a importância do método comparativo em Geografia, visando-se ampliar a reflexão sobre os entraves e as possibilidades de ação nas escalas de gestão local em dois modelos de Estados distintos: o modelo unitário e descentralizado francês e o modelo federal brasileiro. Em um primeiro momento, discute-se o processo de descentralização e as diferenças institucionais entre comunas francesas e municípios brasileiros. A análise se desenvolve nas escalas locais, a partir de informações reunidas durante a realização de entrevistas de campo na região Rhône-Alpes (França) e no estado do Rio de Janeiro (Brasil). Problemáticas que se apresentam nos dois países são enfim discutidas. O objetivo é o de valorizar o método comparativo, ampliando-se o debate sobre o fortalecimento das estruturas de gestão local e as possibilidades de desenvolvimento de práticas de cooperação intermunicipal em dois modelos de Estado distintos.
\end{abstract}

Palavras-Chave: Cooperação, Municípios, Território, Descentralização, Comparação.

\begin{abstract}
This text discusses a set of issues concerning the processes of inter-municipal cooperation developing in France and in Brazil. On the one hand, it brings back some conclusions explored during the realization of surveys made in the region of Rhône-Alpes, in France, and in the state of Rio de Janeiro, Brazil. On the other hand, it examines the influence of the organization of the French and Brazilian States in order to comprehend the particularities of cooperative practices between municipalities in both countries. The objective is to valorise the comparative method, thus expanding the debate about the strengthening of local management structures and the different possibilities of inter-municipal cooperation within two distinct State models.
\end{abstract}

Key words: Cooperation, Municipality, Territory, Decentralization, Comparison.

\section{Résumé}

Ce texte porte sur un ensemble de problématiques concernant les processus de coopération intercommunale qui se développe en France et au Brésil. D’une part, il s'agit de revenir sur quelques conclusions du terrain réalisé dans la Région Rhône-Alpes, en France, et dans l'Etat fédéré de Rio de Janeiro, au Brésil. D'autre part, nous nous interrogeons sur l'influence des armatures institutionnelles de l'Etat français et de l'Etat brésilien pour comprendre les particularités de la pratique coopérative entre communes dans ces deux pays. L'objectif est de valoriser la méthode comparée dans le débat sur le renforcement des échelons locaux de gestion et les manières différentes de concevoir la coopération intercommunale dans deux modèles d'Etat fort différents.

Mots-clés: Cooperation, Municipes, Territoire, Decentralisation, Comparaison.

(*) Bolsista de Pos-Doutorado Junior do CNPq - Pos-Graduação em Geografia da Universidade Federal do Rio de Janeiro Prédio do CCMN - Bloco I - Sala 16 - Cidade Universitária, CEP: 21.945-970 - Rio de Janeiro (RJ), Brasil, Tel/Fax: (+ 55 21) 22707773 / 2590 1308-- jnunesrodrigues@yahoo.com.br 


\section{INTRODUÇÃO}

Ao longo dos últimos vinte anos, uma tendência à descentralização das estruturas político-administrativas dos Estados ocidentais, europeus e latino-americanos ganhou visibilidade. Com a intensificação do fluxo de idéias, pessoas e mercadorias, as sociedades se tornaram mais complexas. A progressiva expansão dos mercados provocou uma maior exigência quanto à transparência e eficiência na satisfação de demandas e prestação de serviços pelo Estado. Além de prestador exclusivo de bens e serviços, o Estado começou a ser percebido como um aparelho regulador, encarregado de estimular as iniciativas da sociedade civil e dos indivíduos. Ademais, com as crises fiscais dos anos 1970 e 1980, o modelo keynesiano centralizado, de controle econômico e político deu sinais de esgotamento, assim como a idéia de Estado-Providência (BENNET, 1990). Nesta lógica, termos polissêmicos, tais como "gestão", "governança", "eficiência", "transparência", "flexibilidade", são freqüentemente convocados para se evocar um novo modo de regulação social, e também as expectativas com relação às performances dos governos.

Ainda que possamos delinear os traços principais, esse processo de desenvolveu de maneira bastante diversa em cada país. Fundamentalmente, se descentralizar significa re-organizar poderes que, em um primeiro momento, estavam mais concentrados, é no âmago de cada estrutura político-administrativa que a descentralização ganha sentido e seu escopo pode ser apreendido. Eis a razão pela qual "descentralizar" se refere antes a uma lógica de mudanças que se reproduz em realidades históricas e políticas precisas (BENNET, 1990, pp.8-9).

Posto isso, torna-se interessante refletir sobre os significados que uma mesma tendência de fortalecimento das escalas de gestão local pode assumir em sociedades que apresentam concepções diversas sobre o Estado e seus mecanismos de controle social. Partindo-se do pressuposto de que as escalas locais ganharam maior visibilidade, trata-se de um contexto privilegiado para o estudo das particularidades sub-nacionais e a maneira como essas últimas afetam a organização do território em escala nacional.

O presente texto interroga sobre a importância da organização político-administrativa dos Estados para a compreensão das práticas de cooperação intermunicipal que se desenvolvem na França e no Brasil. O objetivo é apresentar e debater um conjunto de problemáticas que emergem das práticas cooperativas locais que se desenvolvem em dois modelos de Estado bastante distintos: o modelo tradicionalmente unitário e que se descentraliza francês e o modelo federal brasileiro.

Ainda que França e Brasil constituam realidades sócio-espaciais muito distintas, os dois países atravessaram processos de descentralização de suas estruturas político-administrativas; além disso, assistem à multiplicação de estruturas de cooperação intermunicipal nas escalas locais de gestão territorial.

Nos limites deste artigo, discutiremos algumas constatações que resultam de enquetes de terreno realizadas junto a gestores e responsáveis locais, na Região Rhône-Alpes, na França, e no Estado do Rio de Janeiro, no Brasil. Com o intuito de melhor situar o leitor, algumas características dos modelos de Estado francês e brasileiro serão sublinhadas. Em seguida, abordaremos os procedimentos da pesquisa e a metodologia adotada. Enfim, discutiremos um conjunto de problemáticas que se apresentam nos dois países.

\section{A COOPERAÇÃO INTERMUNICIPAL NA FRANÇA E NO BRASIL, ALGUNS PONTOS DE PARTIDA}

Por cooperação territorial entendemos os acordos voluntários entre duas ou mais estruturas de gestão local (comunas, no caso da França; municípios, no caso brasileiro), voltados à maximização de recursos materiais, humanos e técnicos, capazes de beneficiar o conjunto de estruturas locais participantes. Tais acordos definem regras de funcionamento e de inserção de cada município ou comuna em uma estrutura de cooperação intermunicipal. Essa última se concretiza pela definição 
de novos limites territoriais para enfrentamento de problemas e elaboração de ações conjuntas. As práticas cooperativas intermunicipais tornam-se assim um objeto de estudos eminentemente geográfico: o território "da cooperação" fixado é não somente afetado por políticas públicas, mas constitui o próprio referencial das relações intermunicipais. Em outras palavras, os limites territoriais da cooperação são reconhecidos e compartilhados pelo conjunto de parceiros, o que lhes possibilita identificar problemas comuns e meios de intervenção. Em última instância, "é o território que ordena a cooperação" (JOUVE, 2007, p. 46). O qualificativo "territorial” é assim empregado para valorizar municípios e comunas enquanto espaços políticos, dotados de contigüidade e limites precisos, nos quais os efeitos das ações e decisões do poder público são identificáveis e mensuráveis (CASTRO, 2005).

$\mathrm{Na}$ França, mudanças de ordem jurídica e política estimularam a propagação das estruturas intercomunais. Tais mudanças se referem à evolução da própria legislação nos anos 1990, que estabeleceu as diversas modalidades para o desenvolvimento dos chamados Estabelecimentos Públicos de Cooperação Intercomunal (EPCIs). Leis claras e exaustivas foram importantes para sanar incertezas quanto às pretensões do Estado: a cooperação seria fundada sobre o voluntarismo, diferentemente das tentativas de fusão impostas no passado. Ademais, no contexto europeu, contratos de desenvolvimento territorial são encorajados entre as próprias intercommunalités, ou ainda entre essas e regiões européias localizadas em países diferentes. Em suma, mudanças de ordem institucional e política favoreceram a adoção e a difusão de práticas de cooperação intercomunal na França.

No Brasil, ainda que inauguradas pela Constituição de 1937, uma legislação que dispõe sobre as modalidades de cooperação intermunicipal, na forma de Consórcios Intermunicipais, só foi estabelecida em 2005 . A lei dos Consórcios Públicos foi lançada com o objetivo de sanar incertezas e estimular o desenvolvimento de projetos de gestão consorciada na escala supra-municipal. Nesse quadro, a cooperação entre municípios é reconhecida como um instrumento importante para a gestão de equipamentos, infra-estruturas e serviços urbanos, além de se tratar de uma estratégia eficaz para que os municípios menos populosos sejam capazes de cumprir suas funções.

Diferentemente dos EPCIs franceses, a maior parte dos consórcios brasileiros não visa ao desenvolvimento de projetos territoriais. Antes, o objetivo é elaborar e executar políticas públicas setoriais, comuns aos municípios membros da estrutura intermunicipal. Desse modo, os consórcios promovem a maximização de recursos financeiros, técnicos e humanos, para a criação e manutenção de equipamentos e serviços que, isolados, os municípios seriam incapazes de oferecer. A cooperação intermunicipal se desenvolve assim nos campos da administração, do suporte técnico, de capacitação de pessoal, além da prestação de serviços diretos à população nos ramos da saúde, da educação, do saneamento básico, dos transportes, da assistência social, da cultura e habitação, passando por programas de amparo à infância, de criação de empregos, de desenvolvimento urbano e de proteção ao meio ambiente. Nesse sentido, pode-se dizer que se assemelham aos Sindicatos Intercomunais que fizeram sucesso na França durante os anos 1980. Trata-se de um tipo de cooperação setorial, voltada para objetivos precisos.

Importa ressaltar que a Lei dos Consórcios Públicos propõe alternativas para dois problemas maiores: o problema dos municípios menos populosos, considerados a priori como ineficazes, e o problema das grandes aglomerações urbanas, que exigem o desenvolvimento de ações conjuntas na escala supra-municipal. Embora no Brasil os municípios sejam de porte muito maior do que as comunas francesas - os municípios menores têm menos de 5.000 habitantes, enquanto muitas comunas não ultrapassam a marca de 100 habitantes - é interessante notar que os municípios menos populosos são também taxados de ineficazes, apesar do porte demográfico não constituir explicação suficiente para justificar a penúria financeira.

Em 2005, o Brasil contava com 4537 municípios membros de Consórcios Intermunicipais, o que representa $81 \%$ dos municípios. Nesse conjunto, os municípios menos populosos (menos de 10.000 habitantes) têm ampla participação em Consórcios, sobretudo nos campos da saúde (40\%). 
Com efeito, o ramo da saúde apresenta o maior número de Consórcios (1196 municípios, ou 42\% dos municípios membros de Consórcios), graças às próprias regras do Sistema Único de Saúde (SUS). Descentralização, prevenção e gestão compartilhada, linhas mestras do SUS, estimulam o compartilhamento de recursos para uma melhor resposta às demandas da população. Em seguida ao campo da saúde, aparece o do meio ambiente (9\%), o do saneamento (8\%), do turismo (8\%) e o dos transportes $(7 \%)$.

Apesar das diferenças, tanto os Consórcios brasileiros quanto as intercommunalités francesas seguem a mesma via da cooperação intermunicipal para reforçar o papel das estruturas de gestão local na provisão de equipamentos e serviços públicos. Na França como no Brasil, a cooperação intermunicipal se consolida como uma estratégia para o cumprimento das competências locais, através da maximização das economias de escala. É também importante frisar que o fenômeno da cooperação intermunicipal ganha expressão em um contexto particular: o de valorização das lógicas locais nos processos de definição e tratamento de problemas públicos.

\section{PROCEDIMENTOS DA PESQUISA}

Depois de uma primeira etapa de tratamento de dados estatísticos e de elaboração de mapas na escala nacional da França e do Brasil, selecionamos uma região francesa e um estado federal brasileiro para a realização de nossas entrevistas de campo. Nos limites deste artigo, os resultados da primeira etapa não serão abordados; a intenção é antes sublinhar um conjunto de questões comuns aos dois países, identificadas durante a realização do campo. No âmago das diferenças territoriais brasileiras, o Estado federal do Rio de Janeiro foi selecionado graças à variedade de estruturas intermunicipais que comporta.

Localizado na Região Sudeste do Brasil, o Estado do Rio de Janeiro (RJ) faz fronteira com os Estados de Minas Gerais, São Paulo e Espírito Santo. Trata-se de um dos menores estados brasileiros, contando 92 municípios distribuídos em uma superfície total de $43.696,054 \mathrm{~km} 2$. A população é de 16 milhões de habitantes e sua capital, a cidade do Rio de Janeiro, concentra aproximadamente $40 \%$ do total de habitantes .

É interessante ressaltar que, no Brasil, os estados federados podem criar regiões administrativas, que facilitam a gestão de serviços públicos no conjunto do território estadual. No caso do Rio de Janeiro, as regiões administrativas são as seguintes: Região Metropolitana, Costa Verde, Baixada Litorânea, Centro-Sul, Médio Paraíba, Norte, Noroeste e Serrana.

Na França, a Região Rhône-Alpes foi retida em razão da extensão e diversidade de seu território. Em termos dimensionais, trata-se da única região francesa $\left(43.698 \mathrm{~km}^{2}\right)$, capaz de se comparar ao estado do Rio de Janeiro $\left(43.696,054 \mathrm{~km}^{2}\right.$ ) . No entanto, se as superfícies são próximas, alguns indicadores acusam as disparidades com relação à organização sócio-espacial desses dois espaços sub-nacionais: a população é estimada em 6.160.000 habitantes em Rhône-Alpes $\left(141 \mathrm{hab} / \mathrm{km}^{2}\right)$; o estado do RJ abriga 92 municípios, contra 2879 comunas rhônalpinas .

A Região Rhône-Alpes é um terreno de estudos privilegiado, sendo cruzada por importantes eixos de circulação nacionais e europeus (localiza-se entre o Norte e o Sul da Europa), onde se desenvolvem atividades rurais e urbanas, além de experiências inovadoras em matéria de desenvolvimento econômico e planejamento territorial (JOUVE et al., 2001, p. 35). Trata-se de uma das vinte e duas regiões da França metropolitana, abrigando oito departamentos: Ain, Ardèche, Drôme, Haute-Savoie, Savoie, Isère, Loire et Rhône.

Apesar dos contrastes, os dois conjuntos sub-nacionais selecionados abrigam espaços urbanos e peri-urbanos, assim como áreas rurais menos povoadas. Essa variedade se mostrava interessante para analisarmos as formas e dinâmicas da cooperação intermunicipal nos dois países. Optamos por concentrar a atenção nos espaços periféricos e menos urbanizados, nos quais se concentram os municípios e comunas menos populosos. Tal escolha se justifica em razão de nosso interesse pelas 
vantagens e desvantagens das estruturas de cooperação para os municípios e comunas que se acham distantes das infra-estruturas e serviços à disposição nos grandes centros urbanos. Considerando-se os argumentos que associam o porte demográfico de municípios e comunas a uma suposta ineficácia administrativa e financeira, decidimos investigar até que ponto a cooperação intermunicipal pode ser considerada como solução institucional para municípios e comunas de menor porte.

Depois de uma análise preliminar de mapas temáticos e de estatísticas locais disponíveis tanto para as intercommunalités rhône-alpinas quanto para os consórcios do RJ , um conjunto de estruturas intermunicipais foi selecionado. O objetivo foi o de identificar situações contrastantes, passíveis de ilustrar uma multiplicidade de formas e dinâmicas cooperativas nos dois países. Para tanto, consideramos a localização das estruturas intermunicipais, o número de municípios e comunas participantes, a extensão, as funções desempenhadas, as formas de financiamento, as atividades econômicas predominantes, além de traços sociológicos e culturais particulares desses espaços.

Já em campo, observamos que os Consórcios efetivamente instalados e em funcionamento no estado do RJ eram Consórcios de Saúde. Os outros tipos ora se encontravam em fase de implantação, ora se haviam dissolvido, em razão do término de um programa de governo específico. Isso mostra a ainda incipiente concepção dos gestores sobre o leque de ações capazes de serem desempenhadas pelas estruturas intermunicipais. Por outro lado, o sucesso dos Consórcios de Saúde é explicado pelas próprias regras do SUS, que desde o início do processo de descentralização (anos 1990) incita à gestão consorciada através de um conjunto de normas sobre a questão. Precisamente, as leis que regulam o funcionamento do SUS estimulam a hierarquização de funções entre municípios de porte demográfico diferente. Essa lógica cria uma rede intermunicipal, segundo os equipamentos e infra-estruturas previamente instalados em cada território municipal. A formação de consórcios é assim estimulada para a realização de programas e serviços visando-se em última instância à universalização do acesso aos serviços e programas de saúde (LIMA, 1998, p. 22; ARRETCHE, 2000).

A partir de um conjunto de questões abertas, entrevistamos gestores, funcionários e eleitos locais, notadamente pessoas que desempenham uma função de mediação no processo de constituição da cooperação intermunicipal. Considerando-se as diferenças em termos de extensão e aspectos sócio-econômicos entre municípios brasileiros e comunas francesas, a análise qualitativa das respostas pareceu-nos o método mais adequado para se respeitar a realidade de cada país.

Enfim, a comparação só pode ser realizada se ordenamos a variedade de casos observados. Assim, ao invés de apresentarmos cada estrutura intermunicipal visitada de forma detalhada, optamos pela exposição de um conjunto de temáticas comuns aos dois países, identificadas durante a realização do campo. A partir desse conjunto de informações, esperamos contribuir para o debate sobre os bloqueios e os avanços realizados em matéria de cooperação intermunicipal nos dois países.

\section{FRANÇA E BRASIL: um olhar comparativo}

Os arranjos político-administrativos da França e do Brasil se revelaram importantes para a compreensão da cooperação intermunicipal nos dois países. Na França, a assim chamada "cooperação de projeto", que tem por objetivo o desenvolvimento de projetos globais de desenvolvimento territorial, data dos anos 1990. No entanto, esse tipo de cooperação deriva de formas precedentes, como é o caso de distritos e sindicatos intercomunais. Os distritos e sindicatos, que se propagaram durante os anos 1980, são setoriais, voltados para a provisão de serviços específicos - são, portanto, muito semelhantes aos consórcios brasileiros.

$\mathrm{Na}$ França, observamos certa estabilidade na composição das estruturas intercomunais, que se mantém desde a formação dos primeiros distritos. Essa estabilidade é interessante porque evidencia a reprodução, ao longo do tempo, de laços de reciprocidade entre os mesmos parceiros. A dimensão temporal se apresenta assim como um componente de suma importância para se entender as intercommunalités: quando as estratégias dos parceiros são conhecidas, as incertezas dão lugar à previsibilidade, à estabilidade e à credibilidade nas relações. 
No Brasil, mesmo se a cooperação intermunicipal pode se realizar desde os anos 1930, foi somente após a estabilização do pacto federativo definido em 1988 que a lei 11.105 precisou as modalidades desse instrumento. Um decreto complementar que detalha o disposto na Lei só foi editado em 2007. Isso significa que as experiências em matéria de cooperação intermunicipal são ainda relativamente incipientes. Os laços de reciprocidade entre os parceiros ainda não se estabilizaram e incertezas, assim como o pouco conhecimento de gestores e responsáveis locais acerca das práticas cooperativas, persistem.

Inseridos no arcabouço institucional que regula cada política pública particular, a maior parte dos consórcios visitados deriva de programas de incitação dirigidos pelo Governo Federal e pelos estados federados. Dessa forma, ao inverso do que ocorre na França, onde as iniciativas para a criação das intercommunalités partem dos próprios atores locais, os consórcios se inscrevem na lógica operacional de políticas setoriais e fragmentadas. Dito de outro modo, as relações intergovernamentais e o tratamento vertical das políticas públicas estão na base da cooperação intermunicipal. Os estados federados e o Governo federal são os principais parceiros e financiadores de consórcios, que dificilmente seriam criados sem esse aporte de recursos suplementares. Em síntese, a origem, e de certo modo, o sucesso desses instrumentos, estão associados à capacidade dos municípios de estabelecer acordos com as escalas de gestão superiores.

Ademais, no Estado do Rio de Janeiro as disparidades entre municípios membros de uma mesma estrutura intermunicipal são bastante acentuadas, o que pode dificultar a cooperação. Concretamente, em relação às características demográficas e sociais, existem fortes diferenças entre municípios membros de um mesmo consórcio, o que implica demandas e prioridades diversas no âmbito de um mesmo "espaço de cooperação". Em contraponto, as estruturas intercomunais visitadas na França apresentam perfis sócio-econômicos relativamente semelhantes, sobretudo nos espaços periurbanos. Essa "semelhança" facilita não apenas a definição de prioridades comuns, mas também a requalificação dos espaços mais periféricos, através da criação de oportunidades de investimentos, de atividades produtivas e a geração de novos empregos. Em síntese, a cooperação intermunicipal oferece um novo fôlego às menores comunas, na medida em que se torna um recurso para a renovação das atividades econômicas e a valorização territorial. É igualmente possível avançar a idéia de um tipo de cooperação "défensiva", tanto no Brasil quanto na França, que se caracteriza pela associação de municípios e comunas periféricas que, juntas, buscam contrabalançar o peso econômico e demográfico das cidades principais e das aglomerações urbanas.

Em ambos os países, as divergências se intensificam quando se trata de decidir sobre a localização dos serviços e equipamentos intermunicipais. Nesse quadro, os consórcios parecem reproduzir, em grande maioria, as relações centro-periferia, segundo uma lógica de hierarquização de municípios no provimento de serviços intermunicipais, tal qual definida pelo SUS. De acordo com essa lógica, o município-pólo (que possui geralmente entre 50.000 e 100.000 habitantes) concentra os serviços e equipamentos mais onerosos, e os custos de manutenção são rateados entre todos os municípios de um mesmo consórcio. Tendo-se em vista que os municípios-pólo são freqüentemente submetidos a uma forte pressão sobre seus serviços em razão da migração dos habitantes vindos dos municípios vizinhos, o rateio dos custos constitui uma estratégia eficaz para reduzir os efeitos negativos dessa pressão demográfica. Entretanto, se os serviços permanecem concentrados, os benefícios da cooperação não são igualmente desfrutados por todos os municípios participantes. As péssimas condições de transporte, associadas aos longos trajetos, tornam a cooperação pouco vantajosa para os municípios de menor porte e os mais provincianos. As relações horizontes de reciprocidade terminam assim por se fragilizar. Além disso, as equipes técnicas e de coordenação mudam freqüentemente a cada escrutínio eleitoral, o que dificulta a continuidade dos projetos.

Na França, os conflitos também emergem quando a pauta exige decisão sobre onde serviços e equipamentos serão localizados. No entanto, a proximidade entre comunas faz com que a distribuição espacial de serviços e equipamentos seja menos espinhosa - a proximidade favorece os desloca- 
mentos, embora alguns eleitos protestem contra a concentração de serviços nas comunas-sede da estrutura, geralmente as mais ricas e populosas. Ademais, a possibilidade de arrecadação própria abre caminhos para a redistribuição de recursos no território da cooperação - o saldo positivo dos recursos arrecadados é administrado de forma a reduzir as disparidades intercomunais. Igualmente, o forte engajamento dos eleitos no processo de constituição e na dinâmica de funcionamento dessas estruturas favorece a continuidade dos projetos, assim como a estabilidade das equipes técnicas e de coordenação.

Outro tópico se refere aos limites territoriais da cooperação. Nos dois países foi observada certa correspondência entre os limites das regiões administrativas, definidas pelos estados federados no caso brasileiro, e dos cantões, no caso francês. Na França, os cantões correspondem às circunscrições para a eleição dos conselheiros gerais, que compõem as assembléias legislativas na escala dos departamentos. No Brasil, as regiões administrativas são definidas e organizadas pelos estados federados para uma melhor gestão de serviços específicos, de competência estadual. Essas correspondências sugerem que as escalas do departamento e dos estados federados influenciam a organização dos municípios e comunas na escala local.

No Brasil, considerando-se que o estado não pode obrigar os municípios a se engajarem em estruturas de cooperação, são as medidas de incitação que prevalecem, tais como a elaboração de planos de ação favoráveis à cooperação intermunicipal, a realização de encontros e seminários, o apoio técnico e jurídico, além dos aportes suplementares de recursos financeiros, para ficarmos em alguns exemplos . Segundo essa lógica, o papel dos estados é tão importante que os consórcios respeitam, freqüentemente, os limites das regiões administrativas estaduais. Contudo, essa correspondência quase perfeita leva a interrogações sobre os processos de definição de prioridades e de objetivos comuns entre municípios vizinhos, mas geralmente bastante diversos do ponto de vista sócio-econômico.

$\mathrm{Na}$ França, os departamentos são encarregados de organizar a cooperação intercomunal em seus respectivos territórios. No entanto, muitos gestores reconhecem: apesar da existência das Comissões Departamentais de Cooperação Intercomunal, tal função tem um caráter mais propositivo e consultivo do que impositivo . Na realidade, a coincidência entre limites cantonais e territórios intercomunais revelam uma questão de outra natureza: considerando-se as possibilidades de acumulação de mandatos, a maior parte dos Presidentes das intercommunalités exerce também funções no executivo das comunas, além de serem conselheiros gerais na escala dos departamentos, cujas bases eleitorais são justamente as dos cantões. Ora, tais correspondências de limites e a superposição de funções refletem uma lógica que favorece os eleitos das comunas principais, sedes dos cantões e bases eleitorais dos conselheiros departamentais.

Outro ponto deriva da capacidade tributária das intercommunalités. No Brasil, é inconcebível que um consórcio usufrua da prerrogativa de arrecadar recursos próprios, pelo simples fato de que a arrecadação própria implica o controle de recursos públicos em uma escala de ação diferente daquela de representação política. Assim, os Consórcios são financiados por transferências realizadas por cada município, além das subvenções recebidas das escalas de gestão superiores. Na França, a arrecadação própria amplia as possibilidades de perequação territorial, através de mecanismos de redistribuição do saldo positivo dos recursos arrecadados. Ademais, favorece a margem de manobra sobre investimentos e ações realizadas no território intercomunal. Por conseguinte, o atrelamento dos "autônomos" municípios brasileiros às escalas superiores e a relativa autonomia das comunas francesas nos remetem às mediações do pacto federativo brasileiro e às nuances da cooperação intermunicipal em estruturas político-administrativas distintas. Nessa perspectiva, seriam os municípios brasileiros mais dependentes do que supomos? A questão exige, de todo modo, uma reflexão sobre a complexidade das relações federativas capazes de afetar a adoção de práticas cooperativas intermunicipais. 
O leque de responsabilidades das estruturas intercomunais francesas, associado à possibilidade de arrecadar recursos próprios, suscita outras questões sobre os limites da democracia representativa nesta escala. Os gestores e delegados que detêm o poder decisório nas intercommunalités são eleitos na escala da comuna, para agirem e decidirem em benefício dos habitantes comunais. Ora, na escala intercomunal as decisões afetam e devem beneficiar o conjunto dos habitantes do "território da cooperação", mesmo que tais decisões acarretem desvantagens relativas para algumas comunas. $\mathrm{O}$ vácuo entre a escala da decisão e a escala da democracia representativa coloca assim em xeque a legitimidade dos delegados intercomunais, responsáveis por competências cada vez mais abrangentes, enquanto as tarefas exclusivas das comunas se limitam cada vez mais a questões de ordem administrativa.

No caso dos consórcios, o controle e a participação da sociedade civil ocorrem através dos Conselhos Municipais, que devem regular e debater temas ligados à gestão consorciada. No entanto, muitos dos nossos entrevistados declararam que essa participação é freqüentemente escamoteada: os representantes da sociedade são, em grande parte, representantes de categorias profissionais ou de grupos de pressão particulares, que buscam a obtenção de vantagens junto a gestores. Na França, a sociedade civil é convidada a participar de eventos festivos, feiras ou fóruns de discussão sobre temas pouco polêmicos (como a preservação do meio ambiente, a melhoria da qualidade de vida, entre outros). Em algumas estruturas intercomunais visitadas, consultas públicas costumam ser efetivamente realizadas quando questões pouco consensuais vêm à tona. No entanto, de maneira geral, a comunicação das ações e decisões tomadas ainda é insuficiente, tanto na França quanto no Brasil. A desinformação impera e leva gestores e responsáveis locais a reconhecerem o fraco ou nenhum conhecimento da população a respeito da própria existência das estruturas intermunicipais.

Um último ponto merece ser sublinhado. Na maior parte dos Consórcios, os entraves que se apresentam na escala local se manifestam também na escala intermunicipal. Criados e administrados pelos municípios, os consórcios refletem as incertezas e carências que dificultam a gestão pública local. Desta maneira, quaisquer que sejam as fórmulas, os problemas parecem derivar antes dos limites e bloqueios das administrações municipais, que remetem ao próprio papel do município no pacto federativo brasileiro e ao escopo de suas competências, do que de questões pontuais e localizadas. Em outros termos, pensar nas possibilidades da cooperação intermunicipal exige resgatar o debate sobre a partilha de competências entre os entes da Federação e os recursos disponíveis para executá-las.

\section{CONSIDERAÇÕES FINAIS}

Enfim, as entrevistas realizadas revelaram temáticas similares que derivam das práticas cooperativas intermunicipais que se difundem nos territórios francês e brasileiro. Ao confrontarmos essas duas realidades institucionais mostramos como as experiências em cooperação intermunicipal se concretizam nos dois modelos de Estados. Na França, soluções experimentadas no que tange à localização de serviços e equipamentos, à perequação no espaço intercomunal, ao forte engajamento dos eleitos e à competência tributária das intercommunalités enriquecem a reflexão sobre os entraves e os potenciais dos consórcios brasileiros. Além disso, as enquetes realizadas no Brasil assinalam a persistência de dificuldades, sobretudo no que tange à gestão das distâncias intermunicipais. Essas constatações reforçam a importância da comparação no campo da Geografia Política para se melhor compreender os desdobramentos espaciais das políticas públicas em modelos de Estado distintos.

\section{REFERÊNCIA BIBLIOGRÁFICA}

ARRETCHE, M. Estado Federativo e Políticas Sociais : determinantes da descentralização. Rio de Janeiro/ São Paulo: Revan/FAPESP, 2000. 
BADIE, B., HERMET, G. La politique comparée. Paris: Armand Colin, 2001.

BANDECCHI, B. O município no Brasil e sua função política. São Paulo: Ed. Pannartz, 1983.

BENNET, R. Decentralization, Intergovernmental Relations and Markets: towards a post-welfare agenda?, In: Bennet, R. (ed.). Decentralization, Local Governments and Markets: towards a post-welfare agenda. Oxford: Clarendon Press, 1990. p. 1-28.

BORNAND, E. Raisonner par le territoire : les modalités pratiques de la coopération. In: FAURE, A., Négrier, E. Les politiques publiques à l'épreuve de l'action locale: critiques de la territorialisation. Paris: L'Harmattan, 2007. p. 147-152.

CASTRO, I. E. Geografia e Política: território, escalas de ação e instituições. Rio de Janeiro: Bertrand Brasil, 2005.

CORDONNIER, L. Coopération et réciprocité. Paris: Presses Universitaires de France, 1997.

DUPRE, M., JACOB A., LALLEMENT, M., LEFEBVRE, G., SPURK J. Les comparaisons internationales : intérêt et actualité d'une stratégie de recherche. In: LALLEMENT, M., SPURK, J. (dir.), Stratégies de la comparaison internationale. Paris: CNRS Editions, 2003. p. 7-18.

HASSENTEUFEL, P. De la comparaison internationale à la comparaison transnationale : les déplacements de la construction d'objets comparatifs en matière de politiques publiques. Revue Française de Science Politique, Paris, Presses de Science po, vol. 55, n. 1, p. 113-132. 2005.

LIMA, A.P.G. Os Consórcios Intermunicipais de Saúde e o Sistema Unico de Saúde, Dissertação de Mestrado, Rio de Janeiro: Fundação Oswaldo Cruz, Escola Nacional de Saúde Pública, 1998.

MANN, M. The autonomous power of the State' (1984). In: AGNEW, J. (ed.). Political Geography: a reader. London: New York, Sidney, Auckland, Arnold, 1997. p. 58-81.

MANN, M. The sources of social power: the rise of classes and nation-states, 1760-1914. Cambridge: New York, Cambridge University Press, 1988.

RICHARD, P. ; COTTEN, M. Les communes françaises d'aujourd'hui. Paris: PUF, 1983.

RODRIGUES, J. N. La coopération intercommunale, regards croisés entre la France et le Brésil. Thèse de Doctorat en Géographie, Université Jean Moulin Lyon 3, 2010.

SARTORI, G. Bien comparer, mal comparer. Revue Internationale de Politique Comparée. Bruxelles: De Boeck Wesmael, vol. 1, nº. 1, p. 19-36, 1994.

WEBER, M, Economie et Société t.1. Paris: Plon, 1971.

Trabalho enviado em outubro de 2011

Trabalho aceito em dezembro de 2011 